\title{
Estimation of Terrestrial Solar Radiation and its Variation with other Meteorological Parameters over Lokoja, Nigeria
}

\author{
D. O. Akpootu', M. B. Abubakar ${ }^{2}$, I. Nouhou ${ }^{3}$, M. Idris ${ }^{4}$, M. I. Iliyasu ${ }^{5}$, D. E. Ohaji ${ }^{6}$, S. A. Fagbemi ${ }^{7}$ and \\ A. O. Aina $^{8}$ \\ ${ }_{1,3,6,8}$ Department of Physics, Usmanu Danfodiyo University, Sokoto, Nigeria \\ 2,5Physics Unit, Umaru Ali Shinkafi Polytechnic, Sokoto, Nigeria \\ ${ }^{4}$ Department of Physics, Bayero University Kano, Nigeria \\ ${ }^{7}$ Department of Physics, Federal University Dutsin-ma, Katsina, Nigeria
}

\begin{abstract}
The yearly and monthly estimation of terrestrial solar radiation over Lokoja using meteorological parameters of temperature and relative humidity during the period of twenty two years (July 1983 - June 2005) was investigated. The monthly variation of terrestrial solar radiation with meteorological parameters of global solar radiation, temperature, relative humidity and atmospheric pressure were investigated. The results indicated that high values of terrestrial solar radiation were observed during the rainy season than in the dry season. The highest yearly average values of terrestrial solar radiation observed during the period under investigation were found to be in the year 2005 and 1983 with $378.3521 \mathrm{Wm}^{-2}$ and $368.3232 \mathrm{Wm}^{-2}$ respectively. The highest and lowest monthly values of terrestrial solar radiation were estimated during the rainy and dry seasons in the months of May and January with $385.6133 \mathrm{Wm}^{-2}$ and $358.5111 \mathrm{Wm}^{-2}$ respectively. High values of terrestrial solar radiation with relative humidity and atmospheric pressure were observed during the rainy season and low values during the dry season. The reverse is the case for terrestrial solar radiation with global solar radiation and temperature.
\end{abstract}

KEYWORDS: Global Solar Radiation, Lokoja, Meteorological Parameters, Rainy and Dry Seasons, Terrestrial Solar Radiation.

\section{INTRODUCTION}

Terrestrial radiation is a long-wave electromagnetic radiation in the form of heat energy emitted from the Earth surface and it atmosphere in the temperature range of $200-300 \mathrm{~K}$ [1]. The flux density in the form of energy transported by this radiation is measured in Watt per meter square $\left(\mathrm{W} / \mathrm{m}^{2}\right)$ over the wavelengths of between $4 \mu \mathrm{m}$ and $100 \mu \mathrm{m}$ in the electromagnetic spectrum [1]. Terrestrial radiation depends on the temperature of the radiating body (earth's surface), surface emissivity, atmospheric temperature; water vapor profile and cloud cover [2]. This radiation involves processes of absorption, scattering and emissions from atmospheric gases, aerosols, clouds and the surface.

The lowest layer of the atmosphere generally called the troposphere is closely affected by terrestrial radiation and since this site allows temperature decrease with increasing altitude, warm air near the Earth surface becomes less dense and rises replacing cold air at the upper troposphere. By so doing vertical movement of convective current is produced thereby creating cloud which ultimately rain from the moisture within the troposphere that form part of the weather which we experience [1].

Outgoing longwave radiation (OLR) is classified as type of the radiant energy that leaves out the Earth-atmosphere system to space at a low energy within the sector of the electromagnetic spectrum at a wavelength extended between 4 to $100 \mu \mathrm{m}$; this band of radiation is called infrared radiation (IR) [3]. It is one of the most essential and critical climate processes that contributed to the radiative budget at the top of atmosphere (TOA), any variation in this fundamental component would cause a long-range imbalance net flux, which eventually alters the climate as it adjusts to restore the balance [4]. Radiation emitted from the Earth's surface are absorbed and reemitted in the atmosphere. Again, water vapor pressure has amplifying effects that increase in temperature which caused evaporation of water from the Earth surface that enters the atmosphere as water vapor, absorb and emit radiation through the continuous feedback loop of water vapor that resulted in the overall increase in terrestrial radiation. Thus, temperature has great influence on terrestrial radiation [5].

Greenhouse gases (GHG) such as (water vapor, carbon (iv) oxide, nitrous oxide, methane, and ozone) in Earth's atmosphere absorbs a particular wavelength of the thermal radiation [6]. As a result, the corresponding absorbing layer of the atmosphere emits more radiation due to the extra that adds to the atmosphere. Some of this radiation is downward back towards Earth, which increases the 


\section{International Journal of Current Science Research and Review}

ISSN: 2581-8341

Volume 04 Issue 08 August 2021

DOI: 10.47191/ijcsrr/V4-i8-13, Impact Factor: 5.825

average temperature of the Earth's surface and performs an important part of the global warming [7].

Understanding the spatial and temporal variations of OLR is an important issue in expanding knowledge of water balance dynamics on different scales for water resources management and planning [8]. Typically, the highest values of OLR are correlated with the warmest regions of the Earth's atmosphere, because they radiate the significances amounts of the thermal longwave radiation to space. The cloudless free equatorial trade wind regions and tropical Pacific are affiliated with such high OLR values, while the areas of intense convection associated with monsoon seem as regions of low OLR [9]. OLR is sensitive and dependent on several meteorological variables, and they have a considerable influence on the OLR, among these are the Earth surface temperature (ST), relative humidity $(\mathrm{RH})$ and cloud fraction $(\mathrm{CF})[2]$.

Moreover, accurate knowledge of terrestrial radiation is fundamental to cooling mechanism of Earth atmosphere system. Knowledge of its dependence on surface and atmospheric parameters is therefore relevant for quantitative understanding of climate and of climate change [10]. Also, its knowledge is important to solar engineers and meteorologists to enhance solar energy conversion systems validate remote sensing estimate of solar energy flux and Earth's radiation budget [1].

The purpose of this study is to (i) estimate the yearly and monthly terrestrial solar radiation for Lokoja, Nigeria using the Stefan Boltzmann equation with meteorological parameters of temperature and relative humidity during the period of twenty two years (July 1983 - June 2005) (ii) investigate the monthly variation of terrestrial solar radiation with meteorological parameters of global solar radiation, temperature, relative humidity and atmospheric pressure.

\section{STUDY AREA}

Nigeria being a tropical region has two seasons, the wet and the dry. The wet season is characterized by heavy rainfall. The season falls between the months of April and October. The dry season, on the other hand, is characterized by scanty or no rainfall and dry dust laden atmosphere. The season falls between the month of November and March [11]. In Lokoja, which is the capital of Kogi State, Nigeria, the wet season is oppressive and overcast, the dry season is muggy and partly cloudy, and it is hot year round. Over the course of the year, the temperature typically varies from $66^{\circ} \mathrm{F}$ to $96^{\circ} \mathrm{F}$ and is rarely below $60^{\circ} \mathrm{F}$ or above $101^{\circ} \mathrm{F}$. The study area under investigation is Lokoja (Latitude $7.78^{\circ} \mathrm{N}$, Longitude $6.73^{\circ} \mathrm{E}$ and altitude $62.5 \mathrm{~m}$ above sea level) as shown in figure 1.

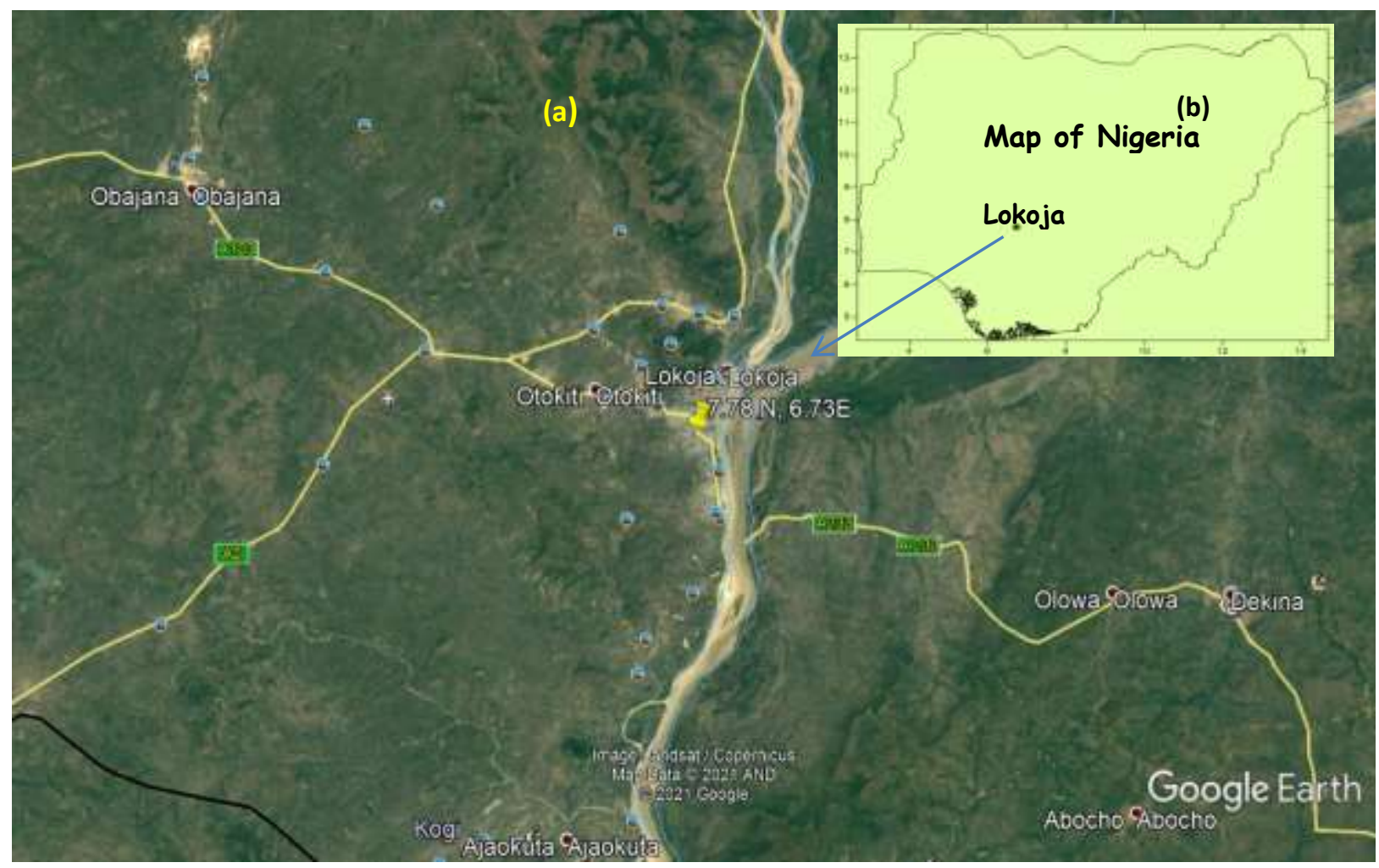

Figure 1. (a) Google map showing the study area (b) Map of Nigeria showing the study area 


\section{International Journal of Current Science Research and Review}

ISSN: 2581-8341

Volume 04 Issue 08 August 2021

DOI: 10.47191/ijcsrr/V4-i8-13, Impact Factor: 5.825

\section{METHODOLOGY}

The measured daily climatic data of temperature and relative humidity utilized in this study for the estimation of terrestrial solar radiation were obtained from the National Aeronautics and Space Administration (NASA) atmospheric science data centre under Surface meteorology and Solar Energy. The daily averaged data were aggregated to monthly data. Similarly, the monthly averaged data were aggregated to yearly data. To avoid possible misleading indications related to year to year variation in weather condition, the period under investigation is twenty two years (July 1983 - June 2005) so as to obtain a good climatological average. The quality assurance of the meteorological measurements was determined by checking the overall consistency of the daily, monthly and yearly average of the meteorological parameter used in the study areas.

Stefan Boltzmann formulated a law that is related to the energy flux density which is proportional to the fourth power of absolute temperature. Because of that, emission of radiation from Earthly bodies changes considerably, even in the limited temperature range characteristics of a single day or season. This can be expressed mathematically as [12]:

$$
E=\varepsilon \sigma T^{4}
$$

where $E$ is the terrestrial solar radiation, $\varepsilon$ is the emissivity of the surface, $\sigma$ is the Stefan Boltzmann's constant which is $5.67 \times 10^{-8}$ $\mathrm{Wm}^{-2} \mathrm{~K}^{-4}$ and $T$ is the temperature measured in Kelvin. Emissivity can be calculated in terms of water vapor using the expression [13]:

$$
\varepsilon=0.605+0.04 e^{0.5}
$$

where $e$ is the water vapor pressure in $\mathrm{hPa}$.

The water vapour pressure, $e$ was obtained using the expression given [14 - 16] as:

$$
e=R H\left(\frac{e_{s}}{100}\right)
$$

where $R H$ is the relative humidity in percentage (\%) and $e_{s}$ is the saturated vapour pressure in $\mathrm{hPa}$.

The saturated vapour pressure was evaluated using the Claussius Clapeyron equation [17] defined as:

$e_{s}$ from equation (4) becomes

$$
\log _{10} e_{s}=9.4051-\left(\frac{2353}{T}\right)
$$

$$
e_{S}=10^{\left[9.4051-\left(\frac{2353}{T}\right)\right]}
$$

In general, changes in temperature $(T)$ and water vapor pressure $(e)$ cause change in the terrestrial solar radiation $(E)$.

\section{RESULTS AND DISCUSSION}

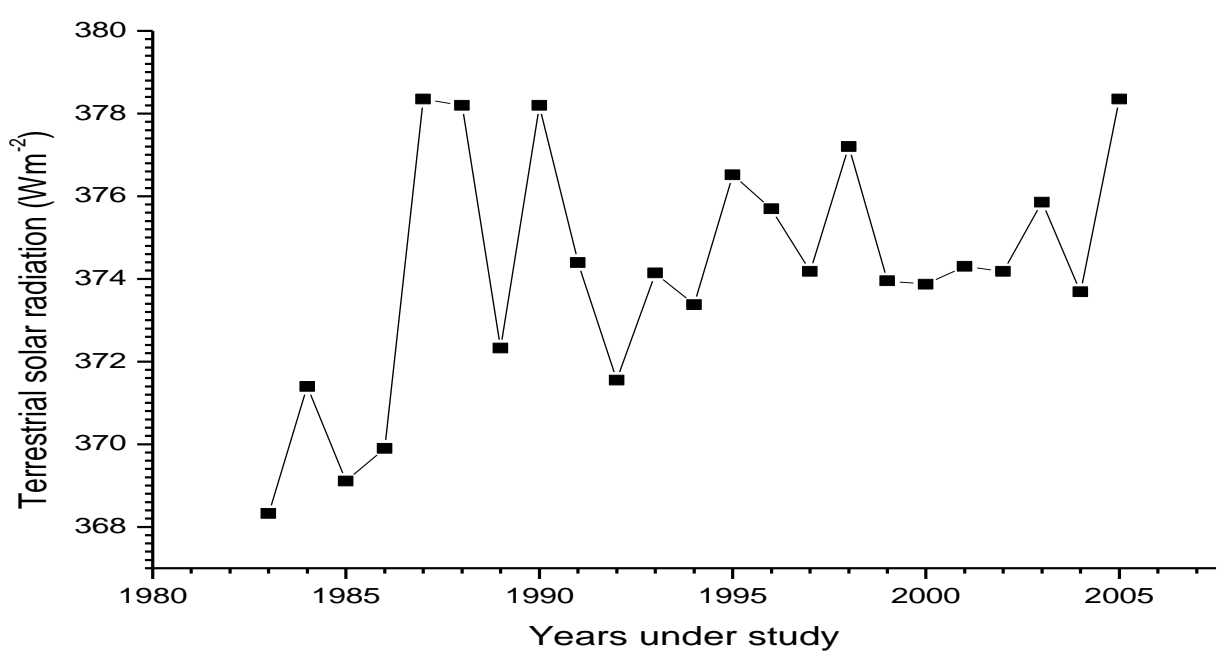

Figure 2. Yearly variation of terrestrial solar radiation for Lokoja 


\section{International Journal of Current Science Research and Review}

ISSN: 2581-8341

Volume 04 Issue 08 August 2021

DOI: 10.47191/ijesrr/V4-i8-13, Impact Factor: 5.825

Figure 2 shows the yearly variation of terrestrial solar radiation for Lokoja during the period under investigation. The result shows fluctuations in the values of terrestrial solar radiation with the highest and lowest values of $378.3521 \mathrm{Wm}^{-1}$ and $368.3232 \mathrm{Wm}^{-1}$ in the year 2005 and 1983 respectively. The mean terrestrial solar radiation during the study period is $374.2195 \mathrm{Wm}^{-1}$.

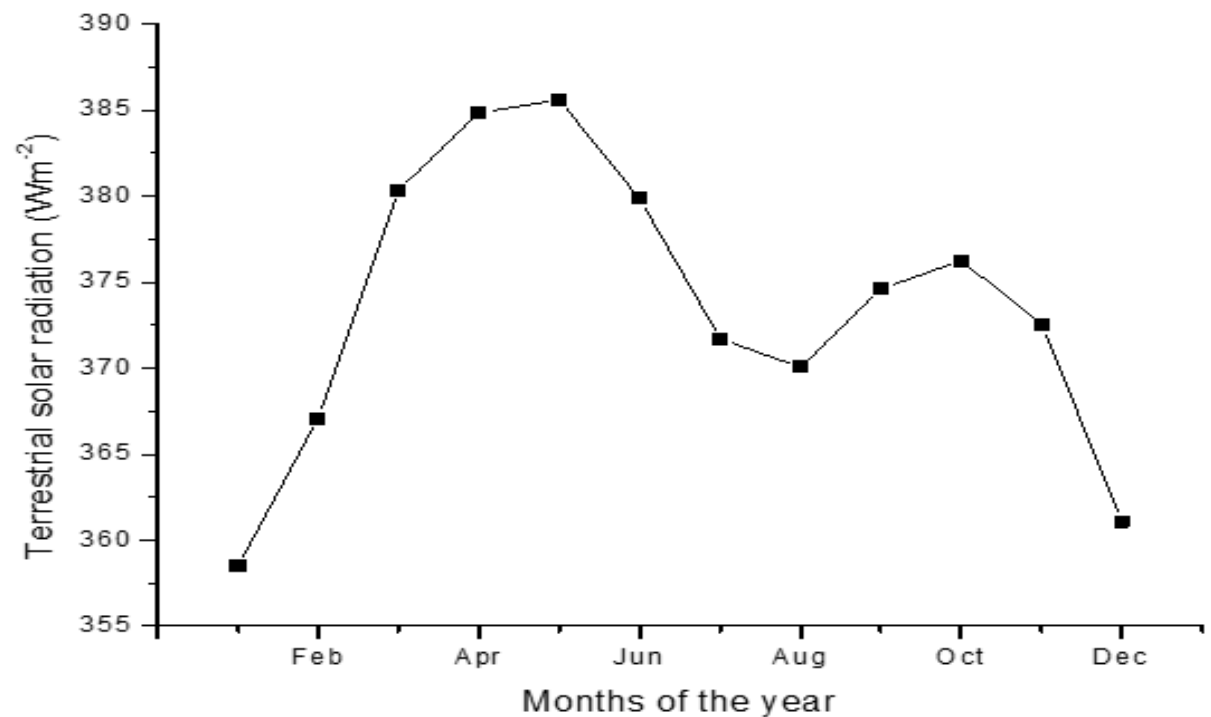

Figure 3. Monthly variation of terrestrial solar radiation for Lokoja

Figure 3 shows the monthly variation of terrestrial solar radiation for Lokoja during the studied period. The values of terrestrial solar radiation increases from its minimum value of $358.5111 \mathrm{Wm}^{-1}$ in the month of January and attained its maximum value of $385.6133 \mathrm{Wm}^{-1}$ in the month of May and then decreases from May to August, the decrease in the value of terrestrial solar radiation in August could be as a result of August break when there is a break in rainfall, this is a phenomenon that usually occur in virtually all the locations across the climatic zones in Nigeria. The terrestrial solar radiation further increases from August to September and then dropped to December. The highest value of terrestrial solar radiation obtained in this study was found in the rainy season in the month of May as $385.6133 \mathrm{Wm}^{-1}$ while the lowest value was found during the dry season in the month of January as $358.5111 \mathrm{Wm}^{-1}$. The result in this study contradicts the findings of Ikeh et al. [1] where they found the highest and lowest values of terrestrial solar radiation to be $400 \mathrm{Wm}^{-1}$ and $381 \mathrm{Wm}^{-1}$ during the dry and wet seasons respectively for Awka, Nigeria. Although, the variation could be as a result of the differences in the climatic condition.

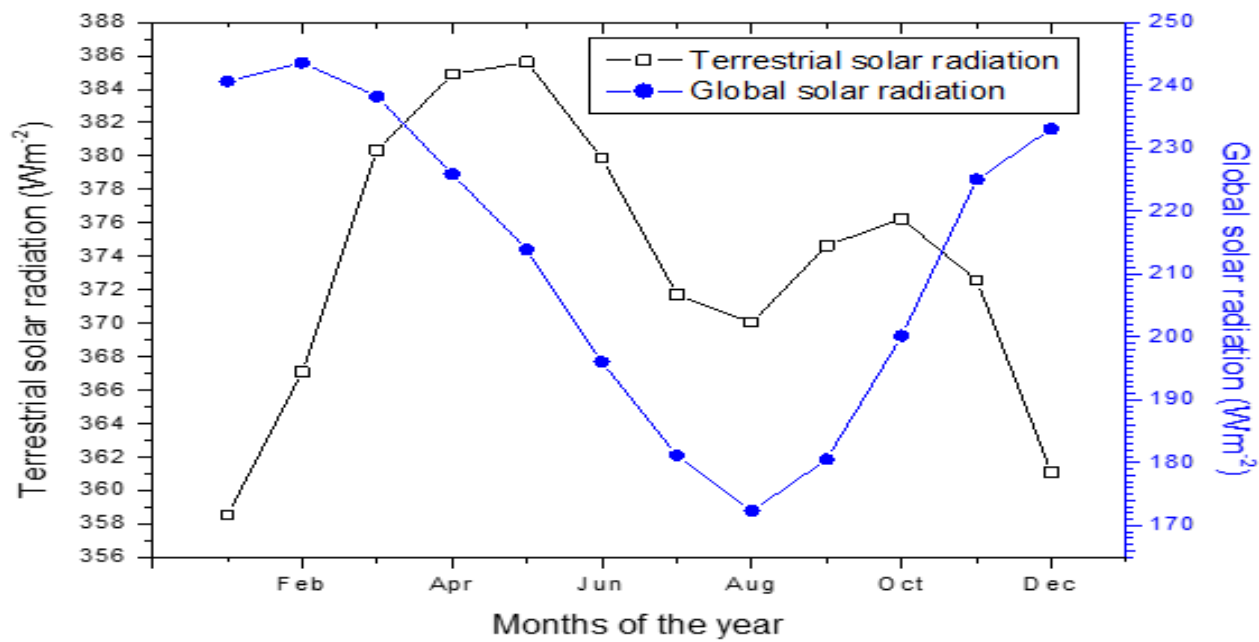

Figure 4. Monthly variation of terrestrial solar radiation with global solar radiation for Lokoja 


\section{International Journal of Current Science Research and Review}

ISSN: 2581-8341

Volume 04 Issue 08 August 2021

DOI: 10.47191/ijcsrr/V4-i8-13, Impact Factor: 5.825

Figure 4 shows the monthly variation of terrestrial solar radiation with global solar radiation for Lokoja during the period under investigation. The result revealed that the global solar radiation increase slightly from January to its maximum value of $243.5922 \mathrm{Wm}^{-1}$ in February and decreases continuously to its minimum value of $172.3729 \mathrm{Wm}^{-1}$ in the month of August and increases to December. The global solar radiation and the terrestrial solar radiation decreases from May to August and increases from August to October; the global solar radiation increases from October to December while the terrestrial solar radiation decreases from October to December. The highest and lowest values of global solar radiation were recorded during the dry and rainy seasons in the months of February and August as $243.5922 \mathrm{Wm}^{-1}$ and $172.3729 \mathrm{Wm}^{-1}$ respectively while the highest and lowest values of terrestrial solar radiation were estimated during the rainy and dry seasons in the months of May and January as $385.6133 \mathrm{Wm}^{-1}$ and $358.5111 \mathrm{Wm}^{-1}$ respectively. The opposite effect observed may be attributed to the fact that the global solar radiation is a short wave electromagnetic radiation emitted from the Sun to the Earth while the terrestrial solar radiation is a long wave electromagnetic radiation emitted from the Earth surface to space. It was observed that the values of terrestrial solar radiation are higher than the global solar radiation throughout the months for the period under investigation.

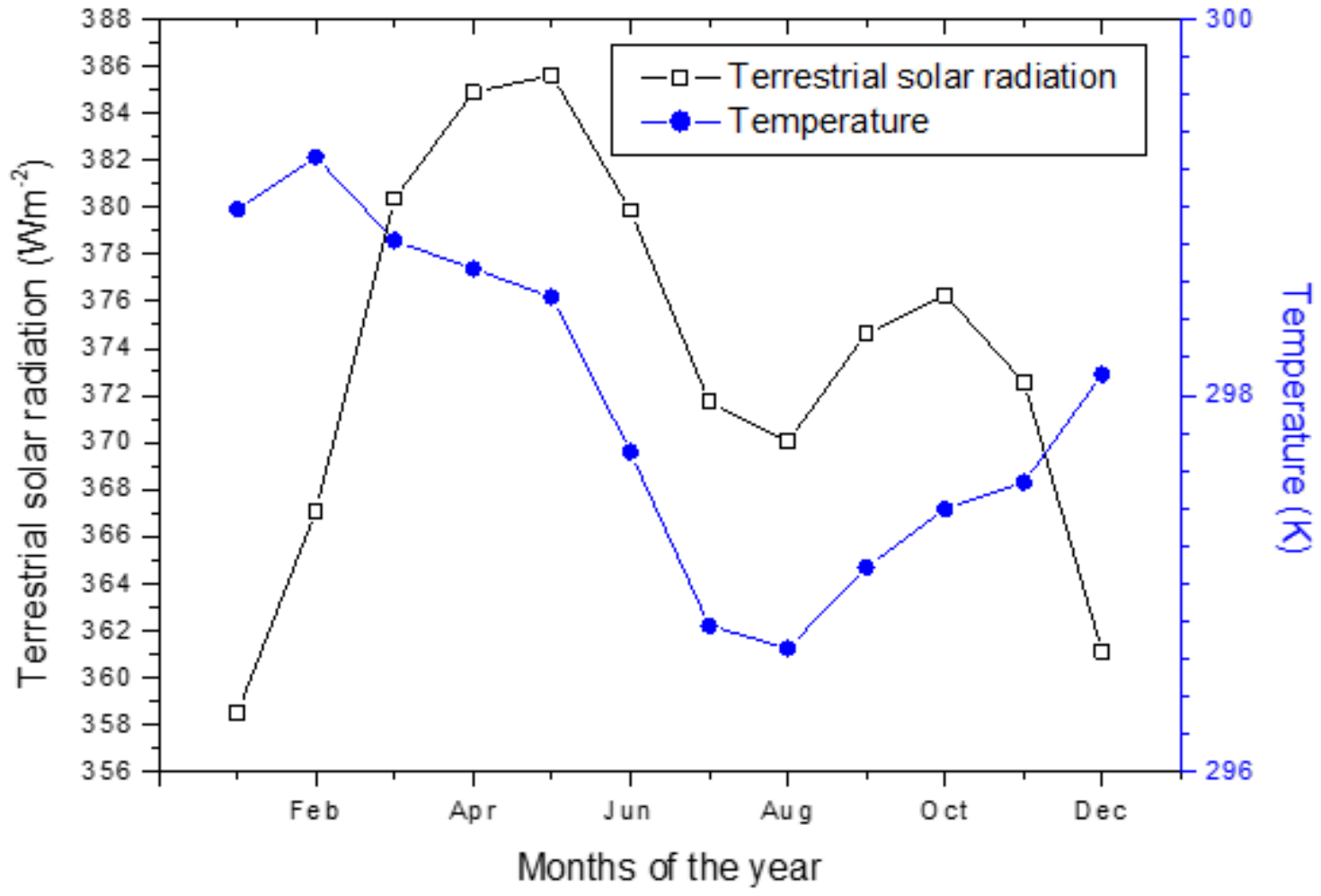

Figure 5. Monthly variation of terrestrial solar radiation with temperature for Lokoja

Figure 5 shows the monthly variation of terrestrial solar radiation with temperature for Lokoja during the studied period for Lokoja. The temperature increases from January to its maximum value of $299.2670 \mathrm{~K}$ in the month of February and then decrease to its minimum value of $296.6562 \mathrm{~K}$ in August; the temperature then increase from August to December. High values of temperature are recorded during the dry season and low values during the rainy season while for the terrestrial solar radiation high values are observed during the rainy season and low values during the dry season. 


\section{International Journal of Current Science Research and Review}

ISSN: 2581-8341

Volume 04 Issue 08 August 2021

DOI: 10.47191/ijesrr/V4-i8-13, Impact Factor: 5.825

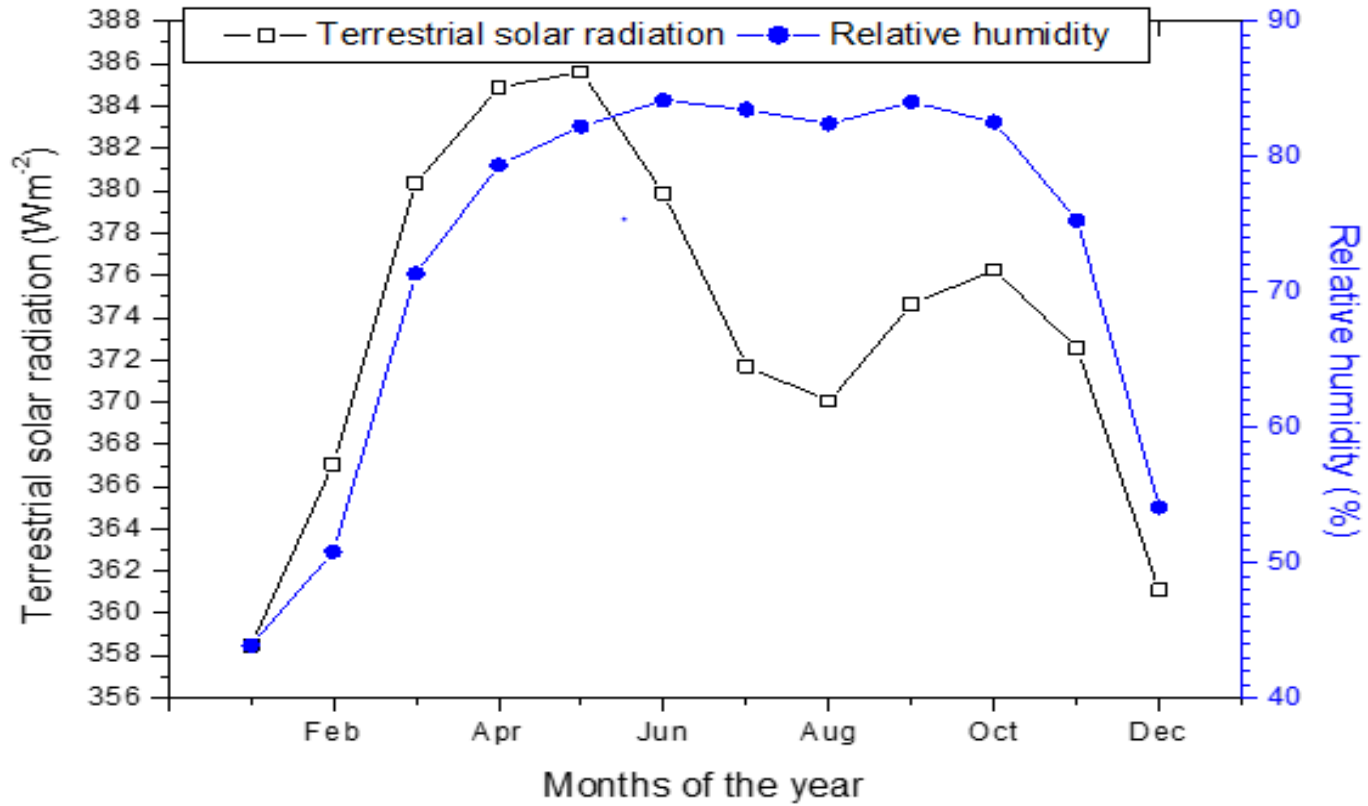

Figure 6. Monthly variation of terrestrial solar radiation with relative humidity for Lokoja

Figure 6 shows the monthly variation of terrestrial solar radiation with relative humidity for Lokoja during the period under study. The terrestrial solar radiation increases with relative humidity from January to May; as the terrestrial solar radiation decreases from May to August the relative humidity increases from May to June and decrease slightly to August. The terrestrial solar radiation increases from August to October and then decrease to December; while the relative humidity increases slightly from August to September and then dropped to December. The highest and lowest values of relative humidity are found during the rainy and dry seasons in the month of June and January with $84.1854 \%$ and $43.8948 \%$ respectively. High values of terrestrial solar radiation and relative humidity are recorded during the rainy season and low values during the dry season.

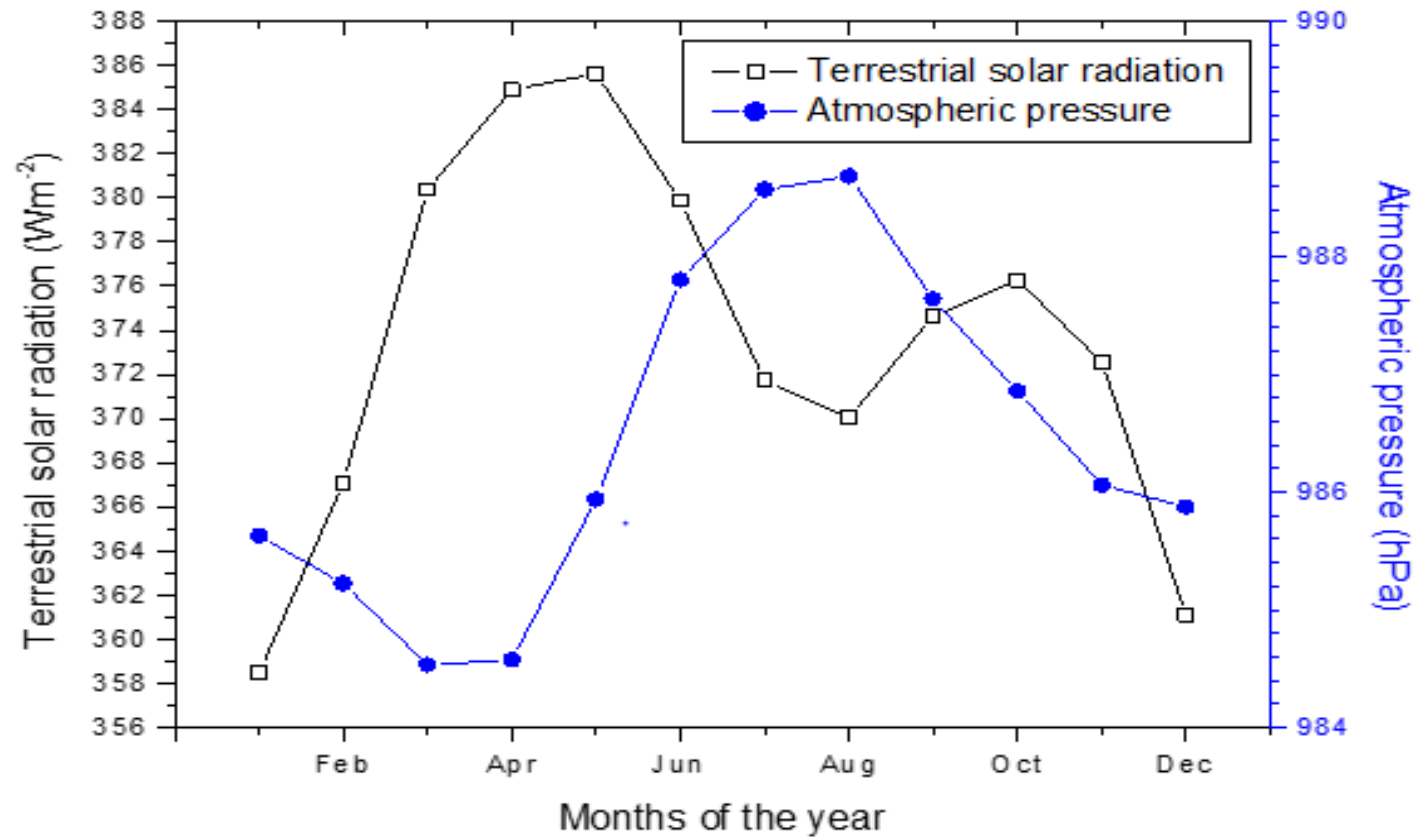

Figure 7. Monthly variation of terrestrial solar radiation with atmospheric pressure for Lokoja 


\section{International Journal of Current Science Research and Review}

ISSN: 2581-8341

Volume 04 Issue 08 August 2021

DOI: 10.47191/ijcsrr/V4-i8-13, Impact Factor: 5.825

IJCSRR @ 2021

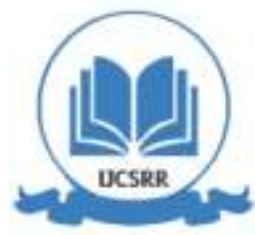

WwW.ijcsrr.org

Figure 7 shows the monthly variation of terrestrial solar radiation with atmospheric pressure for Lokoja during the period under investigation. The atmospheric pressure decreases from January to its minimum value of $984.5321 \mathrm{hPa}$ in the month of March and then increases to its maximum value of $988.6821 \mathrm{hPa}$ in August and then dropped steadily to December. High values of atmospheric pressure and terrestrial solar radiation are recorded during the rainy season and low values during the dry season.

\section{CONCLUSION}

The Stefan-Boltzmann law has been employed to estimate the yearly and monthly average values of terrestrial solar radiation using monthly averaged meteorological parameters of temperature and relative humidity obtained from the National Aeronautics and Space Administration (NASA) during the period of twenty two years (July 1983 - June 2005). The monthly variations of terrestrial solar radiation with meteorological parameters of global solar radiation, temperature, relative humidity and atmospheric pressure during the period under investigation were investigated. The yearly average terrestrial solar radiation indicated that the highest value of $378.3521 \mathrm{Wm}^{-2}$ was found in the year 2005 and the lowest value of $368.3232 \mathrm{Wm}^{-2}$ was found in the year 1983. Furthermore, the results in this study revealed that high values of monthly averaged terrestrial solar radiation were estimated during the rainy season than in the dry season; the highest value of terrestrial solar radiation was found to be $385.6133 \mathrm{Wm}^{-2}$ in the month of May during the rainy season and the lowest value was found to be $358.5111 \mathrm{Wm}^{-2}$ in the month of January during the dry season. The results of the variation of terrestrial solar radiation with global solar radiation revealed that as high values of terrestrial solar radiation were observed during the rainy season low values of global solar radiation were observed, similarly, as low values of terrestrial solar radiation were observed during the dry season high values of global solar radiation were observed, this may be attributed to the fact that global solar radiation is a short wave electromagnetic radiation emitted from the Sun to the Earth and terrestrial solar radiation is a long wave electromagnetic radiation emitted from the Earth to the space, thereby leading to an opposite effect.

\section{ACKNOWLEDGEMENTS}

The authors wish to appreciate the management and staff of the National Aeronautics and Space Administration (NASA) atmospheric science data centre under Surface meteorology and Solar Energy for making all the relevant data used in this present study available online. The contribution and suggestions of the anonymous reviewers are well appreciated.

\section{REFERENCES}

1. Ikeh and Okeke (2019). The Study of Terrestrial Solar Radiation in Awka Using Measured Meteorological Data. Journal of Energy Research and Reviews., 2(4): 1-6.

2. Susskind, J., Molnar., G and Iredell, L (2011). Contribution to climate Research using the Airs science team version -5 products. In SPIE Optical Engineering Applications., 14(5):12-17.

3. Mahakur, M., Prabhu, A., Sharma, A. K., Rao, V. R., Senroy, S., Singh, R. and Goswami, B. N (2013). A high-resolution outgoing longwave radiation dataset from Kalpana-1 satellite during 2004-2012. Current Science, Vol.105, No.8, p. 11241133.

4. Chan, K. P (2013a). Analysis of outgoing longwave radiation (OLR) in different timescales over Africa and Atlantic Ocean. PhD. thesis submitted to Imperial College London. England. pp. 226.

5. Chan K. P (2013b). Analysis of outgoing longwave radiation in different timescales over Africa ocean, imperal college London. 96- 112.

6. AL-Salihi, A. M and AL-Kinani, S. A (2017). Outgoing Longwave Radiation over Iraq using Atmospheric Infrared Sounder. Iranian Journal of Energy and Environment 8(2): 160-169.

7. Mitchell, J. F (1989). The greenhouse effect and climate change. Reviews of Geophysics., Vol.27, No.1, p. 115-139.

8. Lim, E. S., Das, U., Pan, C. J., Abdullah, K. and Wong, C. J (2013). Investigating variability of outgoing longwave radiation over peninsular Malaysia using wavelet transform. Journal of Climate., Vol.26, No.10, p. 3415-3428.

9. Chaudhari, H. S., Shinde, M. A. and Oh, J. H (2010). Understanding of anomalous Indian summer monsoon rainfall of 2002 and 1994. Quaternary International, Vol.213, No.1, p. 20-32. 


\section{International Journal of Current Science Research and Review}

ISSN: 2581-8341

Volume 04 Issue 08 August 2021

DOI: 10.47191/ijesrr/V4-i8-13, Impact Factor: 5.825

10. Allan, R. P., Shine, K. P., Slingo, A and Pamment, J. A (1999). The dependence of clear-sky outgoing long-wave radiation on surface temperature and Relative humidity, 125(5):2103-2126.

11. Agunlejika, O and Raji, T. I. (2010). Empirical evaluation of wet-term of refractivity in Nigeria. International Journal of Engineering and Applied Sciences (IJEAS), 2(2): 63-68.

12. Duarta, H. F., Dias, N. L and Maggiotto, S. R (2006). Assessing daytime Downward longwave radiation estimates for clear and cloudy skies in Southern Brazil. Agriculture and Forest meteorology., 139 (16):171-181.

13. Brunt, D (1932). Notes on radiation in the atmosphere, quarterly Journal of the Royal Meteorological society, 58(5):389418.

14. International Telecommunication Union recommendation, ITU-R (2003). The radio refractive index: Its formula and refractivity data. $453-459$.

15. Adeyemi, B and Ogolo, E. O (2014). Diurnal and seasonal variations of surface water vapour density over some meteorological stations in Nigeria. Ife Journal of Science vol. 16: no. 2.

16. Wagner, W and Prub, A (2002). The IAPWS formulation 1995 for The thermodynamic properties of ordinary water substance for general and Scientific use, 31(2):387535.

17. Akpootu, D. O., Mustapha, W., Rabiu, A. M., Iliyasu, M. I., Abubakar, M. B., Yusuf, S. O and Salifu, S. I (2019). Estimation of Surface Water Vapour Density and Its Variation with Other Meteorological Parameters Over Owerri, South Eastern, Nigeria. Hydrology. Vol. 7, No. 3, pp. 46-55. doi: 10.11648/j.hyd.20190703.12

Cite this Article: D. O. Akpootu, M. B. Abubakar, I. Nouhou, M. Idris, M. I. Iliyasu, D. E. Ohaji, S. A. Fagbemi and A. O. Aina (2021). Estimation of Terrestrial Solar Radiation and its Variation with other Meteorological Parameters over Lokoja, Nigeria. International Journal of Current Science Research and Review, 4(8), 966-973 